Preface

\title{
Oculofacial Plastic and Reconstructive Surgery
}

Douglas P. Marx, MD ${ }^{1}$

${ }^{1}$ Cullen Eye Institute, Baylor College of Medicine, Houston, Texas

Semin Plast Surg 2017;31:3-4.

It is my pleasure to serve as guest editor of this issue of Seminars in Plastic Surgery-Oculofacial Plastic and Reconstructive Surgery. Periorbital and orbital procedures are common operations performed by plastic surgeons. Although these procedures have only a few core principles, it is important for the plastic surgeon to apply these principles in a safe fashion. In my experience, it is the potential complications that make these procedures challenging. In this issue of Seminars in Plastic Surgery, we present articles that highlight techniques in periorbital and orbital surgery.

I would like to express my sincere thanks and gratitude to all the authors who took time from their busy schedules to help make this issue possible. Their dedication, experience, and knowledge are quite evident in these articles, and I greatly appreciate all of them as friends, mentors, and colleagues. I hope the readers will appreciate the wealth of knowledge and expertise they all provide.
Address for correspondence Douglas P. Marx, MD, Cullen Eye Institute, Baylor College of Medicine, 6565 Fannin, NC205, Houston, TX 77030

(e-mail: marx@bcm.edu).
Issue Theme Oculofacial Plastic and Reconstructive Surgery; Guest Editor: Douglas P. Marx, MD
Copyright $\odot 2017$ by Thieme Medical Publishers, Inc., 333 Seventh Avenue, New York, NY 10001, USA. Tel: +1(212) 584-4662.

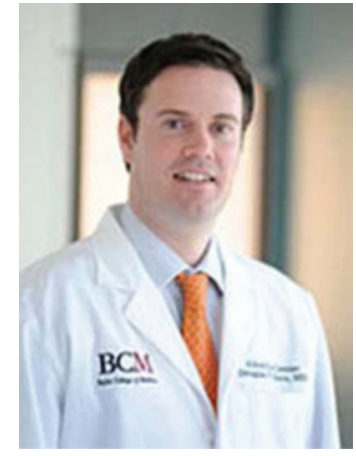

Douglas P. Marx, MD 
